IDEAH • Vol. 2, Iss. 1 (DHSI 2019 \& 2020)

\title{
Bandersnatch-ed \\ Pedagogy: Narrative, \\ Database, and Twine
}

Jon Heggestad ${ }^{1}$

${ }^{1}$ Stony Brook U

Published on: Jul 28, 2021

DOI: 10.21428/f1f23564.bf1d0e27

License: Creative Commons Attribution 4.0 International License (CC-BY 4.0). 


\section{Introduction}

In one of the most watched TED Talks of all time, the Nigerian novelist Chimamanda Ngozi Adichie warns her listeners of what she calls "The Danger of a Single Story" (TED). An avid reader from her early childhood, Adichie recalls that the stories she consumed while growing up in Nigeria were primarily works of British and American literature. This literary diet defined for her what a story could look like, and this ultimately limited the narratives that the future author deemed acceptable to write. Reflecting on her first works of fiction, she remarks, "I wrote exactly the kinds of stories I was reading: all my characters were white and blue-eyed. They played in the snow; they ate apples, and they talked a lot about the weather" (Adichie). Although she makes several lighthearted jokes about the absurdity of these early writing attempts, she concludes, "What this demonstrates, I think, is how impressionable and vulnerable we are in the face of a story." Framed another way, Adichie is showing her audience that a story-or a narrative-does not merely make sense of the world, helping us to organize and understand the events around us; it also constructs the world we encounter and the worlds we are able to imagine.

In the time since writing these first stories, Adichie has discovered a wider array of literature, including books in which she found that "people like me-girls with skin the color of chocolate, whose kinky hair could not form ponytails-could also exist" (Adichie). The novelist has added to this corpus herself. And while contributions like hers and initiatives like We Need Diverse Books have aided in the creation and distribution of a wider array of narratives with which readers might identify or in which they might see themselves reflected, a number of concerns arise from the anecdote Adichie offers. How do we continue to cultivate space for these stories? How do we encourage new stories to be told? In ongoing discussions of how and when to teach canonical texts, where do these new narratives fit? How, in short, can we ensure the stories that have emerged will last? This article offers one possible solution to these questions in looking to the democratic affordances (cf. Gibson; Khost) of database structures. ${ }^{1}$ Although twenty years ago, databases and narratives were framed in competition with one another, this is no longer the case, and as this article aims to illustrate, databases are one site where we might see more diverse and inclusive narratives thrive and multiply.

Beginning with an overview of the theoretical discourses that frame database logic-a model that Lev Manovich uses to describe organizational structures of the Digital Age, as discussed below-this article goes on to posit how databases might be used as tools to 
combat the types of limiting narratives that Adichie encountered in her youth. This democratic turn, however, is not automatic; databases are still digital tools that can be used for any number of purposes. Therefore, after outlining how databases might multiply the number of worlds that readers/users can encounter, I highlight a number of new media artifacts and projects that have encouraged users to engage with these worlds. Many of the examples I address-online archives, digital storytelling platforms, electronic literature, and interactive films-can be understood as modes of interactive storytelling, a field that "aims at creating new media content for the presentation of a narrative, in which the evolution of the story is made dynamic, that is to say it can be modified and/or influenced by the user in real time" (Guerrini 1-2). As is discussed below, dynamic and modifiable stories that grant users the agency to influence a narrative' s direction or outcome offer new opportunities to humanities instructors and students.

This article will focus, in particular, on the freely available and open-source tool Twine. Twine is a digital storytelling platform that operates by way of rhizomatically linked passages (i.e., passages that are connected to one another in disjointed and dispersive ways), making it a useful entry point for both discussing and illustrating how new media objects organized by database logic might provide opportunities for new voices and narratives to be heard. Turning to another and more mainstream new media object that employs the affordances of Twine, I then look to the Netflix interactive

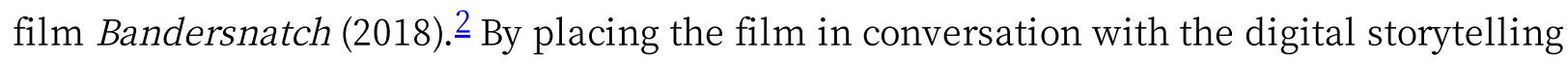
tool, I demonstrate how both might be incorporated into digital humanities (DH) pedagogy as a means of introducing students to the topics of database logic and new media literacy. The last section of this paper looks to my own students' responses to learning about and incorporating database logic in two separate English undergraduate college courses that I teach at Stony Brook University. In bringing Bandersnatch, Twine, and database logic into conversation with more traditional narrative structures, this article ultimately emphasizes the ways in which database logic might reorganize what narratives are told-offering new opportunities for increasing inclusivity.

\section{Narrative and Database}

During the 2018 SXSW EDU Conference, keynote speaker danah boyd asked her listeners, "What Hath we Wrought?" She referred to the state of media literacy in Western education, concluding that the changes in our information landscape, which has become (and will continue to become) more and more complex, require new levels of intervention. "[W]e need to start developing a networked response to this networked 
landscape," she states. "And it starts by understanding different ways of constructing knowledge" (boyd).

Database logic describes one of these prominent new ways of "mak[ing] meaning out of the world," as Manovich observes in The Language of New Media-a text that is already twenty years old but continues to provide useful insights in the present (225). According to Manovich, a database structure refuses to order the items and events we encounter; instead, "every item possess[es] the same significance as any other" (218). Referring to this method of organization as "database logic," Manovich distinguishes it from narrative structure, noting that narratives impose a sense of order by creating "a causeand-effect trajectory of seemingly unordered items (events)" (225). While novels and film have made narrative the privileged form for centuries, Manovich argues that the computer has brought about a new epoch in which database has become the new dominant form. This dominance is seen easily enough in the interfaces of our many streaming platforms and the proliferation of online photo and video repositories. Yet, in making the distinction between these two cultural modes, Manovich frames database and narrative as "natural enemies" whose logics are inherently at odds with one another (225).

Responding to this metaphor, N. Katherine Hayles suggests that narratives and databases actually work together in mutually beneficial ways, altering Manovich's claim to instead depict the two as "natural symbionts" ( "Narrative and Database" 1603). As Hayles points out, narratives are organized by databases, and databases give rise to new narratives. Elaborating on this idea, narratives tend to construct one linear and authoritative story while databases are held together loosely-or relationally, as Hayles observes-and require users to navigate through them on their own. Databases, organized rhizomatically, provide users with a variety of narratives, rather than one solitary, static story. If narratives help us to organize events, databases can help us to organize narratives. As databases gather multiple narratives together, narratives are organized nonhierarchically. In the midst of discussions around canonicity and what counts as great literature, this allows a greater number of works to be viewed alongside one another, on equal grounds-reflecting a frequent goal within digital humanities (cf. Wilkens). And while databases can help us to preserve narratives, they might also allow us to rearrange them, producing new narratives in the process. Thus, databases do not inherently consume narratives, as Manovich earlier claimed; to the contrary, they allow users to create and encounter a greater number of them. 
Yet, this last claim might require even more tentative framing. As Joseph Lloyd Donica notes in his review of Hayles' How We Think-in which Hayles expands on her initial response to Manovich’ s writing-a “measured emphasis on the actual relationship between data and narrative is necessary at a time when film, narrative fiction, and mainstream media consistently frighten publics with the impending war between them" (par. 7). Indeed, fictional works like Enemy of the State (1999) and Minority Report (2002) have predicted contemporary concerns around data surveillance while documentary films like Terms and Conditions May Apply (2013) and The Social Dilemma (2020) continue to draw attention to the dangers brought about by our culture of connectivity (cf. José van Dijck). And Sarah Brayne has recently written about the ways in which governmentcontracted companies like Palantir continue to expand the surveillance state by means of what she calls the "stop-and-frisk database," as controversial policing practices move to digital platforms (31). These examples illustrate the ways in which database logic does not inherently work towards democratizing purposes; as stated above, it is still a tool that can be used in beneficial or harmful ways. As Donica observes, "While narrative explains data, data has become a narrative itself and produced narratives about itself." In slightly amending this assertion, I would emphasize that the ways in which we have employed data and database structures is what has led to the creation of these new narratives, not the data itself. The fact that database logic has so frequently been used as a continuation of Western, patriarchal colonialism is a path that needs correcting, but it can indeed be corrected in order to give way to something much more inclusive and democratic. Developing greater understanding of the other affordances that databases offer is one way that we might begin to change these narratives.

In their reflection on a recent database project, Robert Crease, Elyse Graham, and Jamie Folsom build on Hayles' work, writing, “The kind of database we aim to create [...] should not predetermine the narratives that emerge from it, but rather should allow new narratives to be spotted and created." Although this is their expressed ideal, the writers also observe that embedding a narrative in a database is "inevitable" and that the true danger is in "doing so unreflectively" (53). By acknowledging their own stakes in the project, database creators not only draw attention to their specific positioning but might also highlight, as the creators of the Early Caribbean Digital Archive (ECDA) did, the more democratizing affordances of database structures. $\underline{3}$

The ECDA frames their project as "an experiment in decolonizing the archive using digital means," inviting users to explore, remix, and rethink the materials found in their database ( "Decolonizing" ). In describing their project as one that is "not sequential," but rather "recombinatory" and "relational," the ECDA staff echoes Manovich's 
earlier definition of database logic. One result of this project geared towards digitizing pre-twentieth-century Caribbean archival materials has been the ability to disembed "Caribbean slave narratives from the disparate texts and contexts in which they appear," i.e., from the colonial documents in which these writings were once published (Aljoe et al. 261).

In an example taken from the project' $s$ website, the ECDA "extracted the story of an enslaved woman named Clara from [a] text and placed her name in the identifying category of author" ( "Decolonizing"). This simple act does more than reattribute authorship to Clara; it creates new opportunities as to how Clara and her narrative might relate to the other materials found in the archive and to the archive' s readers as well, challenging the "single narrative" that so often frames material by and about colonized people. It ought to be noted that the ECDA is not only remixing but also reclaiming the archives that have so long been "entwined with colonial European capitalist modernity and a knowledge regime that racializes bodies with the aim of extracting labor, land, and capital from indigenous peoples and enslaved Africans" - the majority of the project' $s$ staff being POC (people of colour) scholars from inter- and multidisciplinary backgrounds ( "Decolonizing"). In asking what would happen if individual narratives were removed from the dominant, Western, white, and imperial narratives in which they have been cast and reproduced for a hundred years or more, the ECDA illustrates that the result is something different, redemptive, and new.

While the ECDA might highlight the benefits of viewing narrative and database as natural symbionts, it also represents a large-scale and well-supported academic digital humanities project (both in terms of funding as well as technological resources). As many scholars, let alone students, are unable to reproduce these conditions in their own work, I now turn to Twine, an open-source digital tool. Originally designed to combat the economic and technological barriers faced by those who desired to author works of interactive fiction, Twine offers an alternative and freely available mode of creating narrative/database projects and developing new media literacies in an interactive and hands-on environment.

\section{Turning to Twine}

Writer, web developer, and game designer Chris Klimas created Twine in 2009 as a platform on which users might write choose-your-own-adventure style stories. Intended as a digital storytelling tool, Twine even refers to projects created on the platform as "stories." In creating a new story, a user simply adds a passage of text and then connects that passage to another. The result is a web of connected passages by which a 
writer is able to create a story that might go in any number of different directions, the ultimate movement through the story being largely dependent on the reader' $s$ choices in navigating the individual passages. Although initially conceived of as a platform for hypertext fiction, Twine has also been adopted as a means of creating interactive games, as passages and the links between them can be edited in any number of ways through "variables, conditional logic, images, CSS, and JavaScript" (Twine). While this gestures to the ways in which the platform functions as a site ripe for experimentation (a necessary value of digital humanities projects, according to Lisa Spiro), it also illustrates-from early on-how Twine began to extend a wide range of digital affordances, as game developers began to use the platform' s existing framework for reasons other than that for which it was originally developed.

This affordance of Twine is often credited to the game developer Anna Anthropy. After writing about Twine and using the platform to create several of her own games in 2012, other prominent independent game creators followed suit, leading to what popular media outlets have referred to as the "Twine Revolution" (Harvey 96). Looking to Twine' s short history, Astrid Ensslin and Lyle Skains observe that the platform functions as a democratizing tool, "first, as a platform for marginalized voices in the gaming industry, and second as a democratization of hypertext as a literary form" (10). In this way, Twine embodies the elements of inclusivity that I have previously noted as an affordance of database logic.

Expanding on the first half of Ensslin and Skains' claim, Alison Harvey posits that Twine' s inclusivity is a result of how the platform "queers game design." By this, she refers to a methodological "queering" - as Twine produces an alternative and more accessible means of creating and distributing games when compared to more traditional routes within mainstream entertainment. She also refers to the ways in which this emerging alterity opens up game design to queer-identifying individuals, as well as other marginalized groups, including (as Harvey notes) “women, genderqueer, and trans* people, poor people, older people, younger people, people of color and first-time gamemakers" (99). Inclusivity was, of course, one of Chris Klimas' intended goals in developing Twine. The "democratization of hypertext as literary form," however, is due in part to the slippages (and the affordances offered through those slippages) that Twine as a platform provided as it was adopted for the creation of both hypertext fiction and games. While these slippages and the possibilities they invited are addressed more fully below, I first examine specific affordances of the software in looking to how Twine has been used by others in the classroom. 
In “ 'Her Story Was Complex' : A Twine Workshop for Ten- to Twelve-Year-Old Girls,” game scholar Kelly M. Tran recounts a study that she conducted to gauge how young girls would approach game design and programming through the Twine platform, noting that this demographic often faces cultural barriers when encountering this field. Hoping that Twine would help users to overcome these barriers, Tran concludes her study with mixed results: "While Twine did not end up engaging girls with programming as much as I had initially hoped, I believe that it is still an excellent tool for creative expression and for allowing students to experiment with game making" (223). Of course, one reason that this study may not have produced the results she anticipated is due to its small number of participants: only eight girls were recruited for the after-school workshop held in a Southwestern US suburb. Tran remains hopeful in looking toward similar future studies, commenting on Twine' s unique ability to "remix" digital culture, referring to the participatory culture of Web 2.0 platforms that might help girls to not only practice "using computers and technology, but produc[e] content as well" (214). An important element to note here is that-like database logic more broadly-the new and inclusive trajectories afforded by Twine in both the realms of game-making and storytelling are not automatic; instead, they indicate one possible direction that users might take with this new media platform.

While Tran' s focus remains on the users' access to digital tools and digital literacy, Adetty Pérez Miles and Kevin Jenkins trace how Twine' s interactive user experience might be applied to "learning about gender identities, trans etiquette, trans ethics, and creating an environment that promotes self-esteem and student success" (44). After addressing the way computer-mediated technologies might enrich instructional scaffolding, Miles and Jenkins outline their own Twine project, titled "Introducing Zoe," observing that their project ultimately allows "undergraduate pre-service art educators to gain a better understanding of gender variance” (45). Using Twine' s choose-your-ownadventure format, they are able to model multiple outcomes to potential classroom scenarios in which users - their pre-service education undergraduate students-encounter the titular Zoe, a transgender student who comes out to the user' $s$ avatar in this simulation in order to discuss her gender identity. As a result of the success of this project, Miles and Jenkins "propose media-rich platforms and interface structures that encourage nonlinear, interactive, and multimodal outcomes and have the potential to expand how we create, consume, and produce text" (46). The majority of their interest lies on the other side of production, however-not with those creating these narratives, but with those consuming them. 
Tran and Miles and Jenkins all highlight Twine' s ability to express and amplify narratives. Yet, none draw specific attention to the database logic that allows Twine to organize and rearrange these stories in new ways. Returning to Manovich's observations surrounding new media, his description of user engagement in relation to database logic maps nicely onto one' s experience of using Twine: “They [stories] appear as collections of items on which the user can perform various operations: view, navigate, search. The user experience of such computerized collections is therefore quite distinct from reading a narrative or watching a film or navigating an architectural site" (Manovich 219). Each of these tasks is accompanied by its own view of "what a world is like," and-as has already been noted-a database presents the world by displaying items and events on equal grounds with one another (219). Addressing Twine as a form of hypertext, Ensslin and Skains' deconstruction of this term (the Greek hypér means “over, above, beyond” while the Latin texeremeans "to weave" ) further emphasizes the database logic under which Twine operates. As the e-lit scholars observe, combining these terms results in a

"subsumption of multiple subordinate texts under a larger organizational, interconnecting protocol” (Ensslin and Skains 2). In this sense, Ensslin and Skains' definition of hypertext is applicable to both Twine and database logic, and as Tran and Miles and Jenkins note above, Twine' s inherent database logic is a useful tool in providing greater agency to storytellers and readers/users alike.

While Twine offers a useful entry point for thinking about the democratizing affordances of databases, there are many other more mainstream examples from popular culture that also lay the groundwork for these theoretical discussions. I now turn to the Netflix original film Bandersnatch to address one such entry point-one which, interestingly enough, is also tied to Twine.

\section{Bandersnatch As Case Study}

The synopsis that Wikipedia offers for the interactive film Bandersnatch comes across as surprisingly vague: “The viewer may have Stefan accept an invitation to Colin' s flat" ;

"If Stefan jumps, he dies" ; "Stefan may choose to fight his therapist" (Wikipedia Contributors). As descriptions of the film's plot, these lines appear hesitant, conditional. Nods to the viewer' s agency and references to endings that may or may not occur are not what one would expect from a film synopsis. But the conditionality of the statements above reflects the branching narratives of Bandersnatch's innovative and interactive structure. "Is there one true, correct path to Bandersnatch?" asks Ben Allen of RadioTimes. "No, and that is kind of the point." 
Bandersnatch asks its viewers to interact with the Netflix streaming platform in order to guide the protagonist, a young programmer named Stefan, as he attempts to break into the video game industry by adapting a fictitious choose-your-own-adventure novel, titled Bandersnatch, into a video game, to be titled Bandersnatch as well. 4 The audience' s viewing experience is constantly interrupted as alternative narrative options appear on screen, prompting viewers to choose which path the film should follow. At first, these choices have little effect on the narrative being constructed. Early in the film, two options appear at the bottom of the screen as Stefan sits down for breakfast, for instance. As he mulls over the cereal boxes on the table before him, the viewer is prompted to assist Stefan in making his choice: "What should he eat? Sugar Puffs or Frosties?" As the film goes on, however, these choices become more consequential. By approximately the ninth set of choices that appear on screen (this depends on which diverging trajectories have previously been selected), the viewer decides whether or not Stefan should take the LSD his coworker offers him: "Yes or no?" Many of these later (and larger) choices dramatically impact the film's plot.

Netflix boasts that there are five unique endings with a number of different variations to each (Allen). Fans of the film have crowdsourced their viewing experiences online in attempts to map out these alternative and parallel storylines through sprawling flowcharts (Garcia et al.). These attempts mirror the ways in which Bandersnatch has built its own database of recorded segments that viewers choose between in navigating their way through the film. Through this process of navigation, however, viewers also actively participate in the narrative' s construction. Perhaps these varying viewing experiences account for why IMDb users' ratings of Bandersnatch are significantly more dispersed than ratings of other installments in the Black Mirror series that follow a more traditional narrative logic-the narratives that viewers encounter within Bandersnatch differing greatly from one experience to another ( "Black Mirror" ; "Black Mirror: Bandersnatch").

While gaming and hypertext fiction communities think of themselves in different ways (cf. Walker Rettberg), Bandersnatch' s critical reception illustrates the slippage between these communities and their respective discourses. The film received many accolades and awards following its release, including two Primetime Emmy Awards and a Broadcasting Press Guild TV and Radio Award, but it also won a Nebula Award in the category of Best Game Writing. What this illustrates is the inherent difficulty of trying to categorize innovative new media productions. A new media object like Bandersnatch crosses the boundaries of what we might expect from works that operate from solely within an individual medium. 
Innovative and original in form, Bandersnatch is of additional interest to this article as it was initially designed on the storytelling platform Twine. Following the film's release, Wired Magazine reported that Charlie Brooker, the film's writer, had relied on Twine, mastering its interface in order to compose the film's sprawling and unconventional script. But accompanying claims that Brooker taught himself to "code" or to write in a "videogame programming language" through Twine are somewhat misleading (Rubin; Reynolds). As is made clear on the platform's homepage, a user does not need any special knowledge of coding to create a story using Twine. While Wired" s claims that the platform may have been "the only way to capture the intra-linked complexity of all the various tributaries and recursions of the Bandersnatchstory" speaks to the platform's unique offerings, their overstatement of Brooker' s “coding” accomplishments works to negate what Klimas and others have noted as Twine' s primary benefit, i.e., its accessibility to all.

In commenting on his own experience using the Twine platform, however, Brooker seems to unknowingly point to a pivotal example of hypertext fiction that reworked more traditional narratives-furthering the connections and slippages between new media objects. "Every time I had an idea I put it in a box, and you can move them around. It' s a bit like making a giant patchwork quilt," he says in explaining the mechanics of the Twine platform (Rubin). Indeed, Shelley Jackson's Patchwork Girl (1995) is an iconic and early example of hypertext fiction, published though Eastgate' s Storyspace software, which Ensslin and Skains identify as Twine' s precursor. Patchwork Girl reworks Mary Shelley' s Frankenstein (1818) in order to give the monster' s intended bride a voice and narrative of her own. This connection points to hypertext' s early use as a medium for offering redemptive or reparative narratives through remediation. $\underline{5}$

\section{Database Logic in the Humanities Classroom}

Seeing that hypertext has historically been used as a tool for remediation, the democratizing affordances of Twine that this essay examines come as no surprise. Twine not only provides a (literal) platform for traditionally marginalized voices but the database logic of hypertext fiction also multiplies the number of narratives we are able to “create, consume, and produce" (Miles and Jenkins 43). Having addressed the ways in which Twine might inform our understanding of database logic, I end this article by pointing to my own students' use of Twine and Bandersnatch in the classroom. First, I look to a theory-driven discussion around Bandersnatch in a digital humanities course that aided students to better comprehend the symbiotic relationship between narrative and database. Second, I highlight students' experimental storytelling through Twine 
during an "Introduction to Fiction" course that enabled them to remediate and even redeem earlier, more traditional, and canonical narratives from our course readings through database logic.

During “Introduction to Digital Humanities," an English course offered at Stony Brook University in the summer of 2019, I assigned Bandersnatch to my students as part of a module geared towards developing new media literacies. After reading Hayles'

"Narrative and Database: Natural Symbionts" and Nicole N. Aljoe, Elizabeth Maddock Dillon, Benjamin J. Doyle, and Elizabeth Hopwood's "Obeah and the Early Caribbean Digital Archive" (both referenced above), students were assigned to watch Bandersnatch, recording the individual paths (or narratives) they created in navigating the film using a digital mapping tool called MindMeister, which allows users to create collaborative mind maps and flowcharts online. Following these tasks, students were given prompts for discussion that included the following questions: how do database and narrative compare to one another? Where do you see the symbiotic nature of database and narrative occurring? How might database logic change the way we approach narratives? What new narratives have databases created? Following group discussion oriented around these prompts, students then wrote a low-stakes reflection on the module that asked them to explore the new opportunities for restructuring narratives that databases afford us.

All twenty students from the class responded positively to these prompts. Following a lively discussion surrounding the questions posed above, student reflections gave voice to continued interest in the affordances of database logic, and a number cited paradigm shifts in how this module had forced them to reflect on the narratives they had previously consumed. For example, one student wrote, "History itself might be conceived as a collection of flexible entities." Other students quickly returned to the topic of database and narrative functioning as natural symbionts in their own reflections. On this theme, one student responded, "[R]esearchers can reshape what is gained from the archive by revising knowledge based upon incorrect and biased narratives." And along similar lines, another wrote, "Reassessing old facts/narratives is an important and even vital task and every so often we find our ideas to have been completely off the mark." These student comments point to wider-reaching applications of narrative/database frameworks. "[T] he past is a collection of different voices," said one final student, noting that databases provide a way to isolate, acknowledge, and amplify a greater range of these voices. In this way, students independently came to the same conclusion about the reparative and redemptive affordances of database structures that hypertext authors like Jackson had envisioned decades earlier. 
While database logic represented a central component of the digital humanities course above, it is present as more of a by-product in many of my other literature courses taught through Stony Brook University' s English department. For the sake of this article, I will focus specifically on an "Introduction to Fiction" course that I taught to undergraduates in the fall of 2018. This course focused on coming-of-age narratives, and one of its primary objectives was to introduce students to a wide variety of authors, genres, and mediums within this thematic framework. As a result, I included a unit on electronic literature that highlighted the democratic affordances of Twine and other born-digital texts. Readings included Anna Anthropy' s "Queers Alive at the End of the World" and Porpentine' s "With Those We Love Alive." As a final project, students were given the option of using Twine to either rework one of our earlier, more traditional readings from the course or author a new and original work that built on themes from the semester while taking advantage of Twine' s choose-your-own-adventure format. For either option, students were expected to include an "appendix," an explanation of how their Twine story built upon and responded to the themes we had discussed. The class was split fairly evenly, with nine students choosing to rework earlier narratives and ten opting to create brand new stories.

Here, I focus on one student' s exemplary final project. Nearing the end of the semester, this student observed that all of our canonical readings from the course ended in tragedy, death, or a general loss of innocence (citing works like Henry James' Daisy Miller (1879), John Knowles' A Separate Peace (1959), and Joyce Carol Oates' 'Where Are You Going, Where Have You Been?" (1966)). Taking issue with the predominant generic message and noting that many college students face enough challenges already, this student decided to compose an original Twine story that offered readers redemptive turns with every passage. Despite branching narratives that dealt with a series of difficult obstacles (that included receiving a college rejection letter, feeling lonely or isolated, and trying to recover from past regrets), the student used Twine as a means of intervening in the narrative that was being constructed in order to provide the reader/user with positive options and trajectories. The title of this Twine project, "You' re Going to Be Okay," emphasized what the student saw as a necessary reworking of coming-of-age narratives.

"Many people in high school and college have already given up on their futures due to thinking they can never get past the hardships they have faced, a way I used to think," this student reflected in her appendix to the project. "With the positive endings I wanted to show that even if things go bad at certain points in your life [...], it will end up being okay." Knowing that she and her peers would continue to encounter "bad surprises" (Sedgwick 12), this student ultimately aligned herself with a reparative reading of the 
texts we had discussed in class. As a result, she produced an interactive text operated via database logic and filled with positive futures. In this pedagogical example, database logic was not a concept that was explicitly discussed in the course; nevertheless, students engaged with the democratizing, redemptive, and agential affordances that databases offer by creating their own hands-on projects with Twine.

Bringing the results of this college assignment alongside the studies from Tran and Miles and Jenkins noted above demonstrates that Twine continues to function as a platform for multiplying new narratives. As an open-source digital storytelling tool organized around database logic, Twine grants a greater degree of agency to its users-both writers and readers alike. In navigating a Twine story, users have the opportunity to construct their own narratives, and this agency can help users to feel less "impressionable and vulnerable" in the face of the narratives they encounter, returning to Adichie' s phrasing from the start of this article. Bandersnatch-ed pedagogy-pedagogy that takes advantage of the democratic affordances found in the database logic of the everyday new media objects we encounter-thus allows students to take ownership of the narratives they encounter. At the same time, as the student comments above illustrate, engaging with database logic also forces us to reckon with this agency. Given these tools, what kind of narratives will we choose to construct and multiply?

\section{Conclusion}

As a response to this last question, we return to the idea that the democratic affordances extended by database logic are not automatic. Bandersnatch not only illustrates the symbiotic nature of narrative and database but additionally functions as a site for critique. As has been observed by scholars including Safiya Umoja Noble, new media objects might afford an opportunity for a greater number of voices to be heard, but they can also easily lead to more of the same, as narratives are recommended and streamed to viewers through black-box algorithms. While Bandersnatch includes an array of narratives, for example, many of its paths reiterate past hegemonic tropes. For instance, all of the employees at Stefan's work as well as all of the gamers he encounters and who are shown throughout the interactive film are male, perpetuating consistent but inaccurate narratives about the inherent maleness of video game culture (cf. Tran). Indeed, Bandersnatch' s entire database of film segments is filled with snapshots of a lone white male up against the world; it fails to pass the Bechdel test and adds little to narratives that feature people of colour and nothing to those that portray LGBTQ+ characters. These aspects are only magnified when viewed outside of the traditional framework of a single story. Yes, Bandersnatch' s database structure multiplies 
narratives, but the many narratives produced in this case portray only what audiences are already able to encounter in abundance when it comes to more traditional mainstream works. Despite the film's shortcomings-or perhaps even through themBandersnatch offers us a useful example for not only understanding the structure and function of database logic but also for turning around and examining the ways in which this logic has been employed. Through this critique, through this new media literacy, students are able to develop a deeper understanding of what democratic affordances database logic holds and how they might better bring out these affordances in their own work.

Developing such literacies is one way to better prepare for the increasingly difficult-tonavigate media landscape identified by boyd above. But in thinking reparatively, database logic helps us to actively engage with a wide range of concerns regarding the representation extended by these objects as well, making space for new voices and new narratives to be heard.

\section{Works Cited}

Adichie, Chimamanda Ngozi. “The Danger of a Single Story.” TED, July 2009, www.ted.com/talks/chimamanda_ngozi_adichie_the_danger_of_a_single_story.

Aljoe, Nicole N., et al. "Obeah and the Early Caribbean Digital Archive." Atlantic Studies, vol. 12, no. 2, June 2015, pp. 258-266. doi.org/10.1080/14788810.2015.1025217.

Allen, Ben. "How Many Endings Does Black Mirror' s Interactive Film Bandersnatch Have?” Radio Times, Dec. 2018, www.radiotimes.com/news/ondemand/2019-07-26/bandersnatch-black-mirror-how-many-endings.

Bandersnatch. Directed by David Slade, Netflix, 2018.

"Black Mirror." IMDb, www.imdb.com/title/tt2085059/ratings?ref_=tt_ov_rt. Accessed 17 Sep. 2020

"Black Mirror: Bandersnatch.” IMDb, www.imdb.com/title/tt9495224/ratings? ref_=tt_ov_rt. Accessed 17 Sep. 2020.

boyd, danah. "SXSW EDU Keynote: What Hath We Wrought?" YouTube, uploaded by

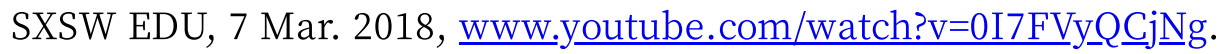

Brayne, Sarah. “Enter the Dragnet.” Logic, vol. 12, Dec. 2020, pp. 19-35. 
Crease, Robert, Elyse Graham, and Jamie Folsom. "Database Thinking and Deep Description: Designing a Digital Archive of the National Synchrotron Light Source." Digital Scholarship in the Humanities, vol. 34, no. 1, Dec. 2019, pp. 46-57. doi.org/10.1093/11c/fqz053.

"Decolonizing the Archive: Remix and Reassembly." Early Caribbean Digital Archive, 9 Aug. 2018, ecda.northeastern.edu/home/about/decolonizing-the-archive/.

Donica, Joseph Lloyd. “Thinking Digitally: A Review of N. Katherine Hayles' s How We Think: Digital Media and Contemporary Technogenesis (University of Chicago Press, 2012)." Digital Humanities Quarterly, vol. 12, no. 1, 2018. www.digitalhumanities.org/dhq/vol/12/1/000369/000369.html.

Ensslin, Astrid, and Lyle Skains. "Hypertext: Storyspace to Twine." Bloomsbury Handbook of Electronic Literature, edited by Joseph Tabbi, Bloomsbury, 2017, pp. 1-22.

Garcia, Janet, et al. "Bandersnatch Map-All Choices and Outcomes.” IGN, 10 Jan. 2019, www.ign.com/wikis/black-mirror/Bandersnatch_Map_-_All_Choices_and_Outcomes.

Gibson, James J. The Ecological Approach to Visual Perception. Psychology Press, 2014.

Guerrini, Fabrizio, et al. "Interactive Film Recombination." ACM Transactions on Multimedia Computing Communications and Applications, vol. 13, no. 4, Aug. 2017, pp. 1-22. doi.org/10.1145/3103241.

Harvey, Alison. “Twine' s Revolution: Democratization, Depoliticization, and the Queering of Game Design.” G.A.M.E.vol. 3, Mar. 2014, pp. 95-107. www.gamejournal.it/3_harvey/.

Hayles, N. Katherine. "Narrative and Database: Natural Symbionts." PMLA, vol. 122, no. 5, Oct. 2007, pp. 1603-1608. doi.org/10.1632/S0030812900168580.

---. How We Think: Digital Media and Contemporary Technogenesis. University of Chicago Press, 2012.

Jackson, Shelley. Patchwork Girl. Eastgate Systems, 1995.

Khost, Peter H. Rhetor Response: A Theory and Practice of Literary Affordance. Utah State University Press, 2018.

Manovich, Lev. The Language of New Media. MIT Press, 2001. 
Miles, Adetty Pérez, and Kevin Jenkins. "(Re)Born Digital-Trans-Affirming Research, Curriculum, and Pedagogy: An Interactive Multimodal Story Using Twine." Visual Arts Research, vol. 43, no. 1, 2017, pp. 43-49. doi.org/10.5406/visuartsrese.43.1.0043.

Noble, Safiya Umoja. Algorithms of Oppression: How Search Engines Reinforce Racism. NYU Press, 2018.

Reynolds, Matt. "The Inside Story of Bandersnatch, the Weirdest Black Mirror Tale Yet.” Wired UK, Dec. 2018. www.wired.co.uk/article/bandersnatch-black-mirror-episodeexplained.

Rubin, Peter. "How the Surprise New Interactive Black Mirror Came Together." Wired, Dec. 2018. www.wired.com/story/black-mirror-bandersnatch-interactive-episode.

Sedgwick, Eve Kosofsky. “Paranoid Reading and Reparative Reading; or, You' re So Paranoid, You Probably Think This Introduction Is about You.” Novel Gazing: Queer Readings in Fiction, edited by Eve Kosofsky Sedgwick, Duke University Press, 1997, pp. 137.

Spiro, Lisa. “'This Is Why We Fight' : Defining the Values of the Digital Humanities." Debates in the Digital Humanities, edited by Matthew K. Gold, University of Minnesota Press, 2012. dhdebates.gc.cuny.edu/read/untitled-88c11800-9446-469b-a3be3fdb36bfbd1e/section/9e014167-c688-43ab-8b12-0f6746095335\#ch03.

TED.www.ted.com/talks? sort=popular. Accessed 7 Sept. 2020.

Tran, Kelly M. “' 'Her Story Was Complex' : A Twine Workshop for Ten- to Twelve-YearOld Girls.” E-Learning and Digital Media, vol. 13, no. 5-6, 2016, pp. 212-226. doi.org/10.1177/2042753016689635.

Twine. https://www.twinery.org. Accessed 18 May 2020.

Van Dijck, José. The Culture of Connectivity: A Critical History of Social Media. Oxford University Press, 2013.

Walker Rettberg, Jill. "Electronic Literature Seen from a Distance: The Beginning of the Field.” Electronic Literature Communities, edited by Scott Rettberg et al., West Virginia University Press, 2015. pp. 11-28.

Wikipedia Contributors. "Black Mirror: Bandersnatch." Wikipedia: The Free Encyclopedia, Wikimedia Foundation, 29 Apr. 2019, 
en.wikipedia.org/wiki/Black_Mirror:_Bandersnatch.

Wilkens, Matthew. "Canons, Close Reading, and the Evolution of Method." Debates in the Digital Humanities, edited by Matthew K. Gold, University of Minnesota Press, 2012. dhdebates.gc.cuny.edu/read/untitled-88c11800-9446-469b-a3be3fdb36bfbd1e/section/6c7cbaa1-5ff8-4439-9ffb-aeccbc6d5734\#ch14.

\section{Footnotes}

1. By “affordance," I draw upon James J. Gibson' s coinage of the term in order to refer to what an environment offers (or affords) an individual. $\bullet$

2. Bandersnatch has also been referred to as Black Mirror: Bandersnatch, the latter title reflecting the film's place within the Black Mirror anthology series. For the remainder of this article, however, I will refer to the film as "Bandersnatch."

3. The ECDA is a project of NULab for Texts, Maps, and Networks at Northeastern University. $\bullet$

4. The confusing nature of this scenario in which film, book, and video game all share the same title is, itself, an echo of the non-sensical absurdity found in Lewis Carroll' $s$ writing, from which the figure of the Bandersnatch is borrowed; it appears in both Through the Looking-Glass (1871) and The Hunting of the Snark (1874). $\bullet$

5. In this context, I use "reparative" in reference to queer theorist Eve Kosofsky Sedgwick' s description of reparative reading. Rather than approaching a text defensively, Sedgwick suggests we "surrender the knowing, anxious paranoid determination that no horror, however apparently unthinkable, shall ever come to the reader as new" (24, original emphasis). If reparative reading engages with surprises and welcomes the new, hypertext makes this method all the more engaging as readers are told to navigate and make sense of or even amends with these surprises. $€$ 